rence, and mortality. Stroke 1992;23:1250-1256.

15. Kaplan EL, Meier P. Nonparametric estimation from incomplete observations. J Am Stat Assoc 1958;53:457-481.

16. Kokmen E, Chandra V, Schoenberg BS. Trends in incidence of dementing illness in Rochester, Minnesota, in three quinquennial periods, 1960-1974. Neurology 1988;38:975-980.

17. Skoog I, Nilsson L, Palmertz B, Andreasson LA, Svanborg A. A population-based study of dementia in 85-year-olds. N Eng J Med 1993;328:153-158

18. Hagnell $O$. Repeated incidence and prevalence studies of mental disorders in a total population followed during 25 years. The Lundby Study, Sweden. Acta Psychiatr Scand 1989; 79(suppl 348):61-77.
19. Hagnell O, Ojesjö L, Rorsman B. Incidence of dementia in the Lundby Study. Neuroepidemiology 1992;11(suppl 1):61-66.

20. Molsa PK, Marttila RJ, Rinne UK. Epidemiology of dementia in a Finnish population. Acta Neurol Scand 1982;65:541-552.

21. Li G, Shen YC, Chen CH, Zhau YW, Li SR, Lu M A threeyear follow-up study of age-related dementia in an urban area of Beijing. Acta Psychiatr Scand 1991;83:99-104.

22. Tatemichi TK, Desmond DW, Paik M, et al. Clinical determinants of dementia related to stroke. Ann Neurol 1993;33:568575.

23. Sauerbrei $W$, Schumacher $M$. A bootstrap resampling procedure for model building: application to the Cox regression model. Stat Med 1992;11:2093-2109.

\title{
Silent brain infarction in nonrheumatic atrial fibrillation
}

\author{
EAFT Study Group*
}

\begin{abstract}
Article abstract-Background: Cerebral infarction associated with atrial fibrillation usually causes permanent neurologic disability, but several studies also reported patients with silent cerebral infarcts on CT. The clinical relevance of this finding is unknown, partly because of variable criteria for the diagnosis of "silent" brain infarction. Methods: This report describes the frequency of silent brain infarcts in 985 patients with nonrheumatic atrial fibrillation, who shortly before suffered a symptomatic transient ischemic attack or nondisabling ischemic stroke, and evaluates the predictive value of silent infarcts for the future development of recurrent vascular events. Results: Of 985 patients, $14 \%$ had CT evidence of brain infarcts not explainable by current or previous episodes of cerebral ischemia. In comparison with symptomatic infarcts, these silent infarcts were more often of the small deep lacunar type (odds ratio 5.1; 95\% confidence interval 3.4-7.7). If silent and zone infarcts occurred, these often involved the territory of the posterior cerebral artery or the right hemisphere. The presence of a silent infarct at entry was associated with an increased risk of vascular events in general and of recurrent stroke in particular. This was due largely to the presence of multiple infarcts on CT. Conclusion: Silent infarcts reflect advanced vascular disease.
\end{abstract}

NEUROLOGY 1996;46:159-165

Atrial fibrillation is associated with a high risk of brain infarction, often causing cardiogenic embolism to the brain. These infarcts most commonly lead to permanent neurologic disability, but several recent studies reported a large proportion with "silent" brain infarcts on CT in this same patient group. ${ }^{1-3}$ These studies, however, were small, and the frequency of silent brain infarcts differed widely (13 to $48 \%$ ). The diagnostic criteria for silent infarcts were variable, however, and it is unclear whether silent brain infarcts are more common in patients with nonrheumatic atrial fibrillation (NRAF) than in other patients with transient ischemic attacks (TIAs) or strokes. The purpose of this study was to assess the frequency of silent brain infarcts in 985 patients with NRAF who recently had a symptomatic TIA or nondisabling ischemic stroke, and to evaluate the predictive value of silent infarcts for the future development of recurrent vascular events.

Methods. Study design. The study considers patients enrolled in the European Atrial Fibrillation Trial (EAFT). ${ }^{4}$ These were patients with NRAF who had suffered a TIA or nondisabling ischemic stroke not more than 3 months before study entry. In total, 1,007 patients were randomized to open oral anticoagulant treatment or to double-blind treatment with aspirin $300 \mathrm{mg} / \mathrm{d}$ or placebo. The original study results showed an impressive risk reduction of vascular events on oral anticoagulant treatment. ${ }^{4}$ Five patients did not satisfy the entry criteria, and for another 17 patients no CT was available, leaving 985 patients for the present analysis.

CT. CT of the brain was mandatory before study entry. All CTs were audited centrally by an independent committee of at least two neurologists. Infarcts were de-

*Collaborating centers have been listed elsewhere (Lancet 1993;342:1255-1262). Writing committee: J.C. van Latum, F. van Kooten, and P.J. Koudstaal (University Hospital Rotterdam Dijkzigt, the Netherlands), J. van Gijn, L.J. Kappelle, and A. Algra (University Hospital Utrecht, the Netherlands).

Supported by grants from the Netherlands Heart Foundation (subs.nr 87.048), Bayer Germany, the UK Stroke Association, University Hospital Utrecht, and University Hospital Rotterdam.

Received November 15, 1994. Accepted in final form May 5, 1995.

Address correspondence and reprint requests to Dr. Peter J. Koudstaal, Department of Neurology, University Hospital Rotterdam Dijkzigt, 40 Dr. Molewaterplein, 3015 GD Rotterdam, The Netherlands. 
fined as hypodense lesions of presumably vascular origin, and they were classified as either end zone (with cortical involvement), border zone (hypodense areas between arterial territories), large subcortical (no cortical involvement, diameter $>15 \mathrm{~mm}$ ), lacunar (small deep lesions with a diameter $\leq 15 \mathrm{~mm}$ ), or lesions in the posterior fossa, comprising both cerebellar and brainstem infarcts. ${ }^{5}$ During the auditing procedure, clinical details were not given until the relevance of the recorded $\mathrm{CT}$ abnormalities had to be assessed. Infarcts were categorized as "currently symptomatic" if their location corresponded with the symptoms of the qualifying event. Focal hypodensities of presumably vascular origin that were not related to the qualifying event were classified as "currently irrelevant" infarcts. The randomization form that was completed for each patient at study entry contained information not only on the symptoms and probable localization of the qualifying event, but also on the occurrence of previous, symptomatic cerebrovascular events (both minor strokes and TLAs) as well as their presumed localization (left or right hemisphere, posterior fossa, left or right eye). Currently irrelevant infarcts on CT that were in keeping with reported cerebrovascular events in the past were further classified as "previously symptomatic" infarcts. If no localizing information was available about previous strokes ( $n=8$ ), the currently irrelevant infarct was classified as probably being a previously symptomatic infarct. Silent brain infarcts were defined as ischemic lesions on CT that were neither symptomatic at the time of randomization nor corresponded with known past events. White matter hypodensity with ill-defined borders was interpreted and recorded as periventricular leukoencephalopathy. ${ }^{6}$

Follow-up CT. Twelve participating centers had a close-out CT made for all patients they had entered in the EAFT ( $\mathbf{n}=76$ ). Additionally, new CTs were made in $\mathbf{1 5 9}$ patients who were reported to have suffered a recurrent symptomatic stroke (including one intracerebral hemorrhage) during the course of the study. These scans were audited by the same committee of neurologists that had audited the study entry CTs. Separate analyses of these CTs were performed in order to assess the occurrence of silent infarction during follow-up.

Data analysis. Univariate analysis of differences between study subgroups was performed with a $t$ test for continuous variables and chi-square statistic for categorical data. For all comparisons, the level of significance was considered to be $p<0.05$. To determine the independent influence of risk factors for silent brain infarction identified by univariate analysis, multivariate analyses were performed with the logistic regression module supplied by the EGRET statistical package. To determine the association between the presence of silent brain infarcts and the occurrence of recurrent vascular events during follow-up, multivariate analyses by means of the Cox proportional hazards model were used.

Results. Baseline $C T$. Of the 985 patients studied, 199 (20\%) had currently irrelevant infarcts on CT. Eleven percent had only currently irrelevant infarcts, and $9 \%$ had both currently symptomatic and currently irrelevant infarcts. In addition, 333 patients (34\%) had only currently symptomatic infarcts, and 453 patients $(46 \%)$ had no infarcts on CT (figure). In total, 668 infarcts were classified

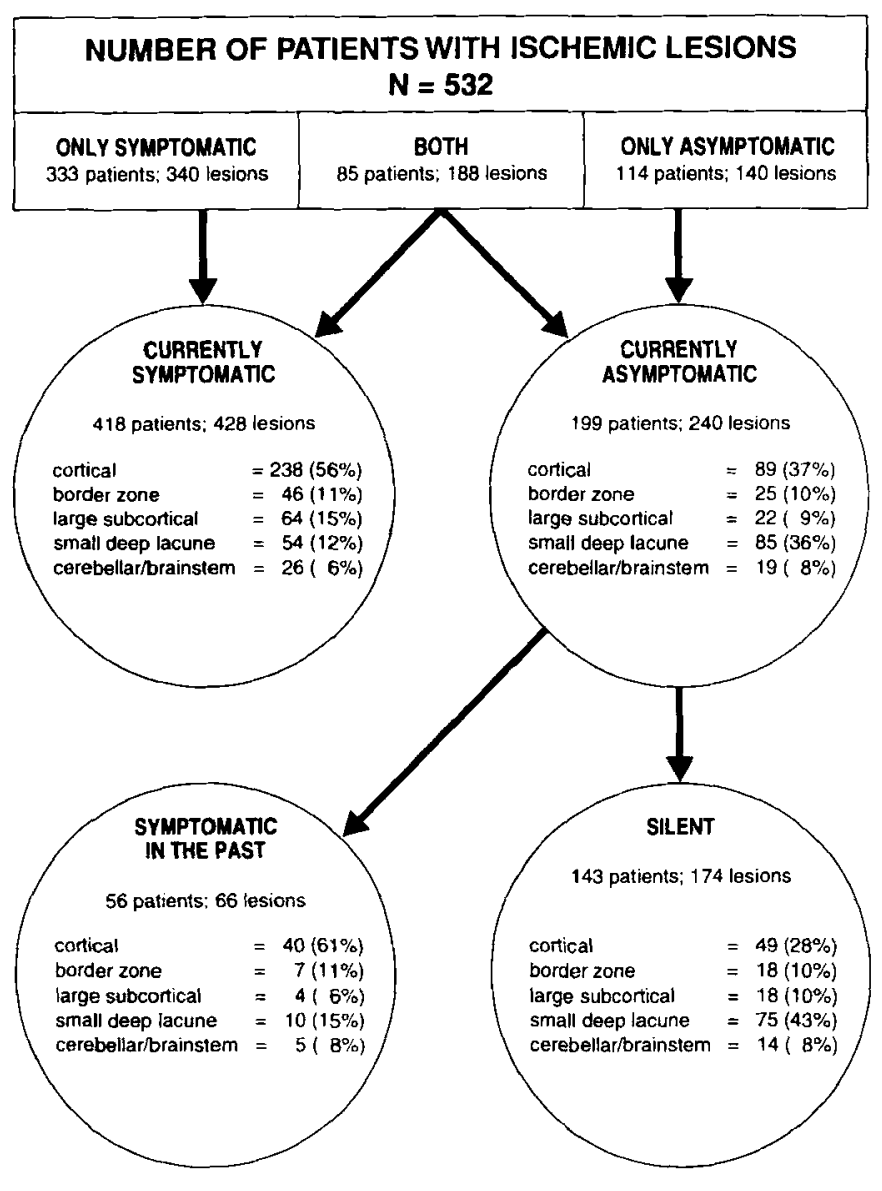

Figure. Frequency and nature of symptomatic and silent brain infarction.

as either symptomatic $(\mathrm{n}=428,64 \%)$ or irrelevant $(\mathrm{n}=$ $240,36 \%$ ). Of the currently irrelevant infarcts, $73 \%(\mathrm{n}=$ 174) could not be explained by previously reported cerebral ischemic events; these infarcts were categorized as silent. Of all patients, $14 \%$ had evidence of silent infarcts on their scan, either with or without concomitant symptomatic infarcts. For the remainder of this paper, the term "symptomatic infarcts" will encompass both the infarcts that were currently symptomatic and those that were symptomatic in the past. Of all silent infarcts, small deep lacunes represented $43 \%$, large subcortical lesions $10 \%$, cortical border zone lesions $10 \%$, cortical end zone lesions $28 \%$, and lesions in the posterior fossa $8 \%$ (figure, table 1). Silent infarcts were significantly more often of the small deep type $(p<0.01)$. Symptomatic infarcts were significantly more often of the cortical end zone type $(p<0.01)$. For patients with both symptomatic and silent infarcts, silent infarcts were found in $23 \%$ of the patients with symptomatic cerebellar or brainstem infarcts, in $15 \%$ of the patients with symptomatic border zone infarcts, in $13 \%$ of the patients with symptomatic end zone infarcts, and in $9 \%$ of those with symptomatic subcortical infarcts (both small and large). These differences were not statistically significant, nor was the type of symptomatic infarct related to the type of silent infarct (end zone, border zone, large subcortical, or lacunar).

In comparison with their silent counterparts, symptomatic lacunes were more often situated in the corona radiata 
Table 1 Silent and symptomatic brain infarctions on baseline $C T$ by stroke type, in patients with nonrheumatic atrial fibrillation. Information on 532 CTs showing a total of 668 ischemic lesions

\begin{tabular}{|c|c|c|c|}
\hline Stroke type & $\begin{array}{l}\text { Silent } \\
\text { infarcts } \\
(n=174)\end{array}$ & $\begin{array}{l}\text { Symptomatic } \\
\text { infarcts } \\
(\mathrm{n}=495)\end{array}$ & $p^{*}$ \\
\hline Small deep lesions & $75(43 \%)$ & $64(13 \%)$ & $p<0.01$ \\
\hline $\begin{array}{l}\text { Anterior limb } \\
\text { internal capsule }\end{array}$ & 7 & 4 & \\
\hline Genu & 1 & 1 & \\
\hline $\begin{array}{l}\text { Posterior limb } \\
\text { internal capsule }\end{array}$ & 8 & 2 & \\
\hline Corona radiata & 10 & 18 & \\
\hline Basal ganglia & 27 & 14 & \\
\hline Thalamus & 12 & 10 & \\
\hline Others & 4 & 2 & \\
\hline $\begin{array}{l}\text { Involving more than } \\
\text { one structure }\end{array}$ & 6 & 13 & \\
\hline $\begin{array}{l}\text { Large subcortical } \\
\text { lesions }\end{array}$ & $18(10 \%)$ & $68(14 \%)$ & $p=0.25$ \\
\hline $\begin{array}{c}\text { Cortical end zone } \\
\text { lesions }\end{array}$ & $49(28 \%)$ & $278(56 \%)$ & $p<0.01$ \\
\hline $\begin{array}{l}\text { Anterior cerebral } \\
\text { artery }\end{array}$ & 1 & 2 & \\
\hline $\begin{array}{l}\text { Middle cerebral } \\
\text { artery }\end{array}$ & 26 & 197 & \\
\hline $\begin{array}{l}\text { Posterior cerebral } \\
\text { artery }\end{array}$ & 22 & 79 & \\
\hline Border zone lesions & $18(10 \%)$ & $53(11 \%)$ & $p=0.89$ \\
\hline $\begin{array}{l}\text { Middle-anterior } \\
\text { artery }\end{array}$ & 3 & 4 & \\
\hline $\begin{array}{l}\text { Middle-posterior } \\
\text { artery }\end{array}$ & 14 & 46 & \\
\hline Deep-superficial & 1 & 3 & \\
\hline $\begin{array}{l}\text { Lesions in the } \\
\text { pasterior fossa }\end{array}$ & $14(8 \%)$ & $31(6 \%)$ & $p=0.53$ \\
\hline
\end{tabular}

* $p$ for comparison of proportions. Chi-square statistic.

( $28 \%$ versus $13 \%$ ) and less often in the posterior limb of the internal capsule ( $3 \%$ versus $9 \%$ ) or in the basal ganglia ( $22 \%$ versus $36 \%$ ); they also more often involved more than one anatomic structure ( $20 \%$ versus $8 \%$ ). Large subcortical infarcts were usually in the territory of the middle cerebral artery; there were no differences in the distribution of sites between silent and symptomatic infarcts of this type. Symptomatic cortical border zone infarcts more often involved the left hemisphere $(66 \%$ versus $39 \%$ of the silent border zone infarcts, $p=0.04$ ). A more or less similar distribution was found for cortical end zone infarcts (57\% of the symptomatic infarcts were in the left hemisphere versus $39 \%$ of the silent infarcts, $p=0.02$ ). Both symptomatic and silent border zone infarcts were usually situated between the territories of the middle and posterior cerebral arteries (85\%). A larger proportion of the silent end zone infarcts involved the territory of the posterior cere- bral artery than of the symptomatic end zone infarcts $(45 \%$ versus $28 \%, p=0.02$ ).

Vascular risk factors and silent brain infarction. Baseline characteristics of the patients in this study group have been summarized in table 2 . In comparison with all other patients (patients with no infarcts on CT and those with only symptomatic infarcts, $\mathrm{n}=842$ ), patients with any silent infarct on CT significantly more often were male ( $66 \%$ versus $54 \%, p=0.006)$ and more often had a history of cardiovascular disease (previous myocardial infarction, intermittent claudication, or angina pectoris) (26\% versus $18 \%, p=0.02$ ). These differences were independent of other risk factors. Duration or type of atrial fibrillation (chronic versus paroxysmal) was not related to the presence of a silent infarct on CT. If the comparison was restricted to patients with symptomatic infarcts on CT, patients with additional silent infarcts $(n=62)$ more often had a history of cardiovascular disease (36\% versus $20 \%$, $p=0.005$ ). In this latter comparison, gender was no longer significantly different ( $66 \%$ versus $55 \%, p=0.09$ ). Of patients with only silent infarcts on their scan $(n=81), 25 \%$ had had a TIA as a qualifying event as compared with $12 \%$ of patients with symptomatic infarcts on their scan and $33 \%$ of patients with no infarcts on their scan.

Silent infarcts on baseline CT and risk of recurrent vascular events. Table 2 also gives an overview of stroke rates (fatal and nonfatal) and vascular event rates in general (vascular death, myocardial infarction, systemic embolism, or stroke, whichever came first). Both event rates increased with the number of infarcts on CT. In accordance with this, both event rates were higher in patients with silent infarcts on their CT. This trend remained the same after correction for differences in treatment allocation (anticoagulants, aspirin, or placebo) and for baseline characteristics in multivariate analyses. Compared with patients in whom the CT was normal, patients with a single infarct had a higher risk for recurrent vascular events in general (hazard ratio $1.5 ; 95 \%$ confidence interval $1.2-1.9 ; p=$ 0.001 ) and for recurrent stroke in particular (hazard ratio $1.7 ; 95 \%$ confidence interval $1.2-2.3 ; p=0.002$ ), similar to patients with two or more infarcts on their scan recurrent vascular events: hazard ratios $1.6 ; 95 \%$ confidence interval $1.1-2.3 ; p=0.009$ and recurrent stroke: 2.2 ; $95 \%$ confidence interval $1.4-3.3 ; p=0.001$. Restricting the analyses only to those patients with visible infarcts on CT, compared with patients who had only symptomatic infarcts on their scan, patients with any silent infarcts (alone, or in combination with symptomatic infarcts) possibly had a slightly higher risk for recurrent vascular events in general (hazard ratio 1.2; 95\% confidence interval $0.9-1.6 ; p=$ 0.3 ) and for recurrent strokes (hazard ratio 1.18 ; $95 \%$ confidence interval $0.79-1.77 ; p=0.4$ ). These estimates were lower, however, after correction for differences in number of infarcts on CT (recurrent vascular events: hazard ratio $1.1 ; 95 \%$ confidence interval $0.8-1.6 ; p=0.5$ and recurrent stroke: $1.0 ; 95 \%$ confidence interval $0.6-1.6 ; p=0.9$ ), suggesting that the risk of recurrent events depends on the extent of ischemic brain damage rather than on whether or not this damage is symptomatic. To illustrate this, in table 3 we have listed the event rates according to the presence of silent infarcts and the total number of infarcts on CT in patients on placebo. 
Table 2 The presence of silent or multiple infarcts on CT in relation to baseline characteristics and outcome events

\begin{tabular}{|c|c|c|c|c|c|}
\hline \multirow[b]{2}{*}{ Characteristics } & \multicolumn{3}{|c|}{ All patients with CT $(n=985)$} & \multicolumn{2}{|c|}{$\begin{array}{l}\text { Patients with infarcts on CT } \\
\qquad(\mathrm{n}=532)\end{array}$} \\
\hline & No infarcts & 1 infarct & $\begin{array}{l}2 \text { or more } \\
\text { infarcts }\end{array}$ & $\begin{array}{l}\text { Only } \\
\text { symptomatic } \\
\text { infarcts }\end{array}$ & $\begin{array}{l}\text { Any "silent" } \\
\text { infarcts }\end{array}$ \\
\hline No. of patients & 453 & 417 & 115 & 389 & 143 \\
\hline \multicolumn{6}{|l|}{ Baseline characteristics } \\
\hline Mean age $\pm \mathrm{SD}$ & $73 \pm 8$ & $72 \pm 8$ & $73 \pm 8$ & $72 \pm 8$ & $73 \pm 7$ \\
\hline Age $>65$ years & $385(85 \%)$ & $344(83 \%)$ & $97(84 \%)$ & $320(82 \%)$ & $121(85 \%)$ \\
\hline Male & $243(54 \%)$ & $237(57 \%)$ & $70(61 \%)$ & $212(55 \%)$ & $95(66 \%)$ \\
\hline Known vascular disease* & $74(16 \%)$ & $83(20 \%)$ & $30(26 \%)$ & $76(20 \%)$ & $37(26 \%)$ \\
\hline History of hypertension & $207(46 \%)$ & $196(47 \%)$ & $60(52 \%)$ & $185(48 \%)$ & $71(50 \%)$ \\
\hline Diabetes & $56(12 \%)$ & $60(14 \%)$ & $12(10 \%)$ & $56(14 \%)$ & $16(11 \%)$ \\
\hline Hypercholesterolemia & $41(9 \%)$ & $39(9 \%)$ & $14(12 \%)$ & $40(10 \%)$ & $13(9 \%)$ \\
\hline Current regular smoking & $87(19 \%)$ & $75(18 \%)$ & $24(21 \%)$ & $70(18 \%)$ & $29(20 \%)$ \\
\hline Hematocrit $>0.45 \mathrm{l} / \mathrm{l}$ & $124(27 \%)$ & $130(31 \%)$ & $34(30 \%)$ & $122(31 \%)$ & $42(29 \%)$ \\
\hline Chronic atrial fibrillation & $345(76 \%)$ & $317(76 \%)$ & $91(79 \%)$ & $297(76 \%)$ & $111(78 \%)$ \\
\hline Duration atrial fibrillation $>1 \mathrm{yr}$ & $248(55 \%)$ & $228(55 \%)$ & $57(50 \%)$ & $210(54 \%)$ & $75(52 \%)$ \\
\hline Cardiothoracic ratio $>50 \%$ & $97(22 \%)$ & $109(26 \%)$ & $25(22 \%)$ & $95(24 \%)$ & $39(27 \%)$ \\
\hline TIA as qualifying event & $147(33 \%)$ & $55(13 \%)$ & $18(16 \%)$ & $45(12 \%)$ & $28(20 \%)$ \\
\hline White matter hypodensity on $\mathrm{CT}$ & $84(19 \%)$ & $54(13 \%)$ & $27(24 \%)$ & $54(14 \%)$ & $27(19 \%)$ \\
\hline
\end{tabular}

\section{Outcome events}

Vascular events, all $\neq$

$\begin{array}{ccc}114(12 \% / \mathrm{yr}) & 145(17 \% / \mathrm{yr}) & 41(20 \% / \mathrm{yr}) \\ 68(7 \% / \mathrm{yr}) & 93(11 \% / \mathrm{yr}) & 31(14 \% / \mathrm{yr})\end{array}$

$131(16 \% / \mathrm{yr})$

$55(22 \% / \mathrm{yr})$

Strokes, fatal and nonfatal $\uparrow$

$68(7 \% / \mathrm{yr})$

$93(11 \% / y r)$

$88(11 \% / \mathrm{yr})$

$36(14 \% / \mathbf{y r})$

* History of previous myocardial infarction, intermittent claudication, or angina pectoris.

+ Crude event rates only. Event rates differed depending on treatment allocation (placebo, aspirin, or oral anticoagulants), but the trend toward increasing event rates by increasing number of ischemic lesions remained the same after correction for treatment allocation. Vascular events include vascular death, stroke, systemic embolism, and myocardial infarction.

CT = computed tomography; TIA = transient ischemic attack

Follow-up CTs. Of the 76 scans made at the end of the EAFT trial (mean interval, 2.19 years), two showed evidence of both new symptomatic (recognized in the course of the study and classified as outcome events) and new silent infarcts, nine of only symptomatic new infarcts, nine of new infarcts with no known symptoms (other than, in some cases, general deterioration of cognition), and one showed only a new infarct that was clearly associated with the event at baseline (obviously the first CT had been made too early, within 24 hours). In total, $14 \%$ of all closeout scans showed evidence of silent infarction (event rate 7 per 100 patient-years; $95 \%$ confidence interval 3-12 per 100 patient-years). Five of the silent infarcts occurred in patients randomized to placebo $(\mathbf{n}=30)$, four events occurred in patients in the aspirin group ( $n=30$ ), and two in patients on anticoagulants $(n=16)$.
We also evaluated scans made at the time of a possible recurrent symptomatic cerebrovascular event, about which we had information in 159 patients. Apart from some in farcts related to the qualifying event that had not yet been seen on the baseline CT ( $\mathrm{n}=11), 48$ scans showed no new infarcts, 88 showed only new symptomatic infarcts, nine showed only new silent infarcts, and 14 showed both new symptomatic and new silent infarcts. In conclusion, 14\% ( 23 of 159) of all CTs made at the time of a symptomatic recurrent stroke (mean time between outcome event scan and baseline scan, 1.29 years) showed evidence of silent infarction (event rate 11 per 100 patient-years; $95 \%$ confidence interval 7-17 per 100 patient-years). Nine of 73 placebo-treated patients, 12 of 70 aspirin-treated patients, and 2 of 16 anticoagulant-treated patients had new silent infarcts on their outcome event CT. 
Table 3 Event rates (per 100 patient-years) stratified for number of infarcts on CT and presence of silent infarcts in patients randomized to placebo treatment

\begin{tabular}{|c|c|c|c|c|c|}
\hline \multirow{2}{*}{$\begin{array}{l}\text { No. of } \\
\text { infarcts }\end{array}$} & \multirow{2}{*}{$\begin{array}{l}\text { No. of } \\
\text { patients }\end{array}$} & \multicolumn{2}{|c|}{$\begin{array}{c}\text { All vascular events* (vascular death, } \\
\text { stroke, MI, SE) }\end{array}$} & \multicolumn{2}{|c|}{ All strokes (fatal and nonfatal) } \\
\hline & & No. of events & Event rate & No. of events & Event rate \\
\hline No infarcts & 155 & 41 & $13 / 100$ pyr & 25 & 8/100 pyr \\
\hline \multicolumn{6}{|l|}{ Only sympt } \\
\hline 1 & 135 & 56 & $22 / 100$ pyr & 39 & $15 / 100$ pyr \\
\hline$\geq 2$ & 12 & 5 & $20 / 100$ pyr & 3 & $12 / 100$ pyr \\
\hline \multicolumn{6}{|l|}{ Any silent } \\
\hline 1 & 27 & 11 & $22 / 100$ pyr & 7 & $14 / 100$ pyr \\
\hline 2 & 31 & 12 & $25 / 100$ pyr & 7 & $14 / 100$ pyr \\
\hline$\geq 3$ & 6 & 5 & $100 / 100$ pyr & 5 & $100 / 100$ pyr \\
\hline
\end{tabular}

* Whichever came first.

$\mathrm{MI}=$ myocardial infarction; $\mathrm{SE}=$ systemic embolism; Only sympt $=$ patients with only symptomatic infarcts on their scans; pyr $=$ patient-years.

Discussion. In our study cohort of 985 patients with NRAF who underwent neurologic evaluation because of a recent (less than 3 months ago) TIA or minor ischemic stroke, $20 \%$ had evidence of unrelated ischemic lesions on their CT. In $14 \%$ of all patients, the unrelated ischemic lesions could not be explained by symptomatic episodes of cerebral ischemia in the more distant past. Kempster et $\mathrm{al}^{2}$ reported finding asymptomatic infarcts in $13 \%$ of NRAF patients who, like ours, had presented with recent symptoms of cerebral ischemia. In NRAF patients with no known history of previous or current cerebral ischemia, Petersen et $\mathrm{al}^{3}$ reported a markedly higher rate of asymptomatic infarcts $(48 \%)$, as did Feinberg et $\mathrm{al}^{4}(26 \%)$. The results of Kempster et al, and of the current study, are in accord with the proportion of silent infarcts found in other patients with recent symptomatic cerebral ischemia (10\% to $13 \%)^{7-9}$ the only exception being the communitybased study of Ricci et al, ${ }^{10}$ which reported a frequency of silent infarction of $38 \%$ in first-ever stroke patients.

A potential limitation of our study is the generalizability of data collected in the context of a clinical trial to the overall population of NRAF patients with a recent stroke. Nevertheless, the results seemingly contradict the notion that NRAF is associated with an unduly high risk of silent brain infarction. NRAF is, however, associated with a higher overall rate of ischemic lesions on CT, sometimes multiple; in total, 668 ischemic lesions were present on the scans of the NRAF patients ( 0.7 lesion per patient), compared with only 969 lesions on the scans of the 2,329 patients in the comparable patient cohort of the Dutch TIA Study (0.4 lesion per patient). ${ }^{11}$ The main difference between these studies is that the TIA study included patients in sinus rhythm who had suffered a recent minor ischemic stroke or TIA.
Comparisons between studies are difficult because it is hard to establish uniform criteria for the diagnosis of silent or asymptomatic brain infarction. Discrepancies relate first to problems in identification of ischemic lesions on CT and second to the classification of these lesions as symptomatic or asymptomatic. With respect to the first, evaluations can be biased by differences in the quality of the scans, and there is reason to assume a considerable inter-observer variation in identifying ischemic lesions. ${ }^{12}$ Identification of silent ischemic lesions is, for instance, impeded by the inability to relate the suspected ischemic lesion to abnormalities found at neurologic examination. With respect to the second problem, studies differ in the extent to which they acknowledge that previous transient neurologic symptoms can also be associated with relevant brain infarcts on CT. ${ }^{10,11,13}$ Additional sources of error include an inadequate history or insufficient recording of the precise nature of neurologic symptoms. Symptoms related to cerebrovascular events may not have been recognized by patients or their physicians, particularly if brief or occurring during the night. Minor symptoms such as limb numbness, clumsiness, rotational vertigo, and dysarthria may have other etiologies than brain ischemia. Overall, the distinction between silent and symptomatic brain infarction is, to some extent, artificial and arbitrary, and there should be more attention given to the broader concept that silent infarction signifies evidence of previous cerebrovascular events. Moreover, multiple silent infarcts can take a cumulative toll on a patient's cognition and therefore become "symptomatic" over time. ${ }^{14}$ Finally, this study shows that the association between asymptomatic lesions on $\mathrm{CT}$ and a relatively high rate of recurrent vascular events or strokes can be explained by the presence of multiple 
ischemic lesions rather than by whether these lesions were symptomatic.

The event rate for new asymptomatic cerebral ischemia (7 per 100 patient-years) found in this study seems high, and was even higher for patients with recurrent symptomatic events ( 11 per 100 patient-years). This latter estimate is biased by the selection of high-risk patients. Whether the frequency of new asymptomatic cerebral ischemia is higher in NRAF patients than in other stroke patients remains uncertain, but the recurrence rate for symptomatic stroke (10 per 100 patient-years in aspirin-treated patients $)^{4}$ in this same study population is higher than that reported by studies of hospital-referred non-NRAF patients ( 3 to 4 per 100 patient-years $)^{15-17}$ and of the same magnitude as the recurrence rate of asymptomatic infarcts in NRAF patients. This supports our belief that the pathogenesis and prognostic importance of asymptomatic or silent infarcts is no different from that of symptomatic strokes. Any differences should probably be ascribed to specific properties of the underlying lesions. For instance, in this and other studies, small deep infarcts were more often asymptomatic than large infarcts with cortical involvement, and their natural history may differ from that in other stroke subtypes. ${ }^{18}$ Eliasziw et al ${ }^{19}$ have recently reported no difference in prognosis between TIA patients with and without a cerebral infarction on CT. This finding is in agreement with earlier reports, ${ }^{5}$ but appears to be different from our present findings. The results of the two studies cannot be directly compared, however, since the study of Eliasziw et al was limited to patients with TLAs and a high-grade carotid stenosis and since the infarcts on CT in their study were not asymptomatic.

The duration of atrial fibrillation, as far as known, was not related to the presence of asymptomatic lesions in this study or to the number of ischemic lesions (symptomatic and asymptomatic) on CT, nor was it related to the rate of recurrent vascular events (unpublished observation). These findings might imply that the presumed causal relation between atrial fibrillation and (embolic) stroke is not strong, atrial fibrillation being predominantly a marker for the extent of atherosclerotic disease in the patient, and the ischemic lesions resulting from small vessel disease. This lack of association can, however, also be explained by inadequate ascertainment of the exact time of onset of atrial fibrillation in the individual patients. Atrial fibrillation is often asymptomatic, and a brief episode of paroxysmal atrial fibrillation may precede the onset of permanent atrial fibrillation. ${ }^{20}$

In conclusion, patients with NRAF are at high risk of stroke. Some of these cerebral ischemic events will be symptomatic, whereas others, because of site or size, will be asymptomatic. In either event, as patients suffer more ischemic episodes, symptomatic or not, their risk for recurrent stroke or other vascu- lar events further increases. Less attention should be focused on the presence of silent ischemic brain lesions alone, since the term "silent" is often badly defined and sometimes confusingly used in patients who actually had related, transient, cerebrovascular events. ${ }^{21}$

\section{Acknowledgments}

The authors gratefully acknowledge the help of the following centers that were prepared to make close-out CTs in their EAFT patients: Hospital La Paz, Madrid; Hospital del Mar, Barcelona; Centre Hospitalier, Bourg-en-Bresse; Centre Hospitalier, Besançon; Centre Hospitalier, Meaux; Ospedale R. Silvestrini, PerugiaSan Sisto; Stichting Oosterscheldeziekenhuizen, Goes; Canisius Wilhelmina Ziekenhuis, Nijmegen; Hospital de Santa Maria, Lisbon; Hospital Geral de Santo Antonio, Porto; Hospital de San José, Lisbon; Hospital de Santa Cruz, Lisbon.

\section{References}

1. Feinberg WM, Seeger JF, Carmody RF, Anderson DC, Hart RG, Pearce LA. Epidemiologic features of asymptomatic cerebral infarction in patients with nonvalvular atrial fibrillation. Arch Intern Med 1990;150:2340-2344.

2. Kempster PA, Gerraty RP, Gates PC. Asymptomatic cerebral infarction in patients with chronic atrial fibrillation. Stroke 1988;19:955-957.

3. Petersen P, Madsen EB, Brun B, Pedersen F, Gyldensted C, Boysen G. Silent cerebral infarction in chronic atrial fibrillation. Stroke 1987;18:1098-1100.

4. EAFT Study Group. Secondary prevention in non-rheumatic atrial fibrillation after transient ischaemic attack or minor stroke. Lancet 1993;342:1255-1262.

5. Koudstaal PJ, van Gijn J, Lodder J, et al, for the Dutch TIA Trial Study Group. Transient ischemic attacks with and with out a relevant infarct on computed tomographic scans cannot be distinguished clinically. Arch Neurol 1991;48:916-920.

6. Van Swieten JC, Hijdra A, Koudstaal PJ, van Gijn J. Grading white matter lesions on CT and MRI; a simple scale. J Neurol Neurosurg Psychiatry 1990;53:1080-1083.

7. Chodosh EH, Foulkes MA, Kase CS, et al. Silent stroke in NINCDS Stroke Data Bank. Neurology 1988;38:1674-1679.

8. Herderscheê D, Hijdra A, Algra A, et al, for the Dutch TIA Trial Study Group. Silent stroke in patients with transient ischemic attack or minor ischemic stroke. Stroke 1992;23: $1220-1224$

9. Kase CS, Wolf PA, Codosh EH, et al. Prevalence of silent stroke in patients presenting with initial stroke: The Framingham study. Stroke 1989;20:850-852.

10. Ricci S, Celani MG, La Rosa F, Righetti E, Duca E, Caputo N. Silent brain infarctions in patients with first-ever stroke: a community-based study in Umbria, Italy. Stroke 1993;24:647651 .

11. Koudstaal PJ, van Gijn J, Frenken CWGM, et al, for the Dutch TIA Trial Study Group. TIA, RIND, minor stroke: a continuum or different subgroups? J Neurol Neurosurg Psychiatry 1992;55:95-97.

12. Rienhoff O, Stoppler L, Grunwald F, Schmidt R, Zeidler U. Interobserver variability in CT reporting: a comparative evaluation. Neuroradiology 1978;16:322-323.

13. Bogousslavsky J, Regli F. Cerebral infarct in apparent transient ischaemic attack. Neurology 1985;35:1501-1503.

14. Ratcliffe PJ, Wilcock GK. Cerebrovascular disease in dementia: the importance of atrial fibrillation. Postgrad Med J 1985; 61:201-204.

15. Candelise L, Vigotti M, Fieschi C, et al. Italian multicenter study on reversible ischemic attacks. VI. Prognostic factors and follow-up results. Stroke 1986;17:842-848.

16. Dutch TIA Trial Study Group. Predictors of major vascular events in patients with a transient ischemic attack or nondisabling stroke. Stroke 1993;24:527-531.

17. UK-TIA Study Group. United Kingdom transient ischaemic 
attack (UK-TIA) aspirin trial: interim results. BMJ 1988;296: $316-320$.

18. Bamford J, Sandercock P, Dennis M, Bum J, Warlow C. Clas sification and natural history of clinically identifiable subtypes of cerebral infarction. Lancet 1991;337:1521-1526.

19. Eliasziw M, Streifler JY, Spence JD, Fox AJ, Hachiuski VC, Barnett HJM, for the North American Symptomatic Carotid
Endarterectomy Trial (NASCET) Group. Prognosis for patients following a transient ischemic attack with and without a cerebral infarction on CT. Neurology 1995;45:428-431.

20. Petersen P, Godtfredsen J. Embolic complications in paroxysmal atrial fibrillation. Stroke 1986;17:622-626.

21. Caplan LR. Silent brain infarcts. Cerebrovasc Dis 1994 4(suppl):32-39.

\title{
Isolated infarcts of the pons
}

\author{
Claudio Bassetti, MD; Julien Bogousslavsky, MD; Alain Barth, MD; and Franco Regli, MD
}

\begin{abstract}
Article abstract-We studied 36 patients with MRI-proven isolated acute pontine infarct. Corresponding to the constant territories of intrinsic pontine vessels, infarcts followed a predictable distribution, enabling us to delineate three main syndromes. Twenty-one patients had a ventral pontine infarct. Motor involvement varied from mild hemiparesis (ventrolateral pontine syndrome) to severe hemiparesis with bilateral ataxia and dysarthria (ventromedial pontine syndrome). In addition, three-fourths of the patients had clinical evidence for usually mild tegmental dysfunction. Eleven patients had a tegmental pontine infarct, presenting tegmental signs (eye movement disorders, cranial nerve palsies, sensory disturbances), and mostly mild motor deficits (tegmental pontine syndrome). Only four patients had alternating deficits, and these never corresponded to any of the so-called classic pontine syndromes. Infarcts in the medial and the extreme lateral tegmental territory were never observed in isolation, being always associated with cerebellar or larger (and multiple) infarctions in the posterior circulation. Four patients with a bilateral ventrotegmental pontine infarct presented with acute pseudobulbar palsy, bilateral motor deficits, and tegmental signs.

The results of etiologic work-up emphasize the concept of basilar artery branch disease, which was the most common presumed cause of stroke $(16 / 36,44 \%)$. Basilar artery branch disease was particularly associated with large ventral infarcts, severe clinical symptomatology, progressive or fluctuating course, and local recurrence. Presumed small-artery disease $(9 / 36,25 \%)$ was usually associated with small ventral or tegmental infarcts and rapidly improving lacunar syndromes. Large-artery stenosis $(8 / 36,22 \%)$ and cardioembolism $(1 / 36,3 \%)$ were less common than in series of posterior circulation infarcts that include simultaneous pontine and extrapontine lesions.
\end{abstract}

Recovery was good in two-thirds of the patients, the worse outcome being associated with large ventral infarcts.

NEUROLOGY 1996;46:165-175

The reports of the so-called classic pontine syndromes ${ }^{1}$ of Millard-Gubler (1855-56, caudal ventral pontine syndrome-ie, homolateral facial palsy and contralateral hemiparesis ${ }^{2}$ ), Foville (1858, caudal tegmental pontine syndrome-ie, homolateral gaze palsy and facial palsy, contralateral hemiparesis), and Raymond-Cestan (1903, rostral tegmental pontine syndrome-ie, homolateral gaze palsy, contralateral hemihypesthesia and ataxia) constituted the basis for the first classification of pontine strokes, by Dejerine. ${ }^{3}$ Reviewing clinico-pathologic studies up to 1911, Marburg expanded the knowledge on pontine stroke symptomatology, describing "convulsions" (first mentioned by Nothnagel ${ }^{4}$ ), monoappendicular motor deficits, crural ataxia, and the "herald hemiparesis" ${ }^{5}$ of bilateral pontine infarctions. ${ }^{6}$

Duret $(1873)^{7}$ and Stopford $(1916)^{8}$ made the first outline of the constant and predictable ventral, lateral, and dorsal arterial territories of the pons. In 1925, Foix and Hillemand took over and expanded this new information. They correctly stressed the rarity of "classical" pontine syndromes, suggesting a new classification of pontine strokes in paramedian, tegmental, and lateral syndromes. ${ }^{9}$ Shortly thereafter, Lhermitte and Trelles added the description of a bilateral pontine syndrome with pseudomedullary paraplegia. ${ }^{10}$

Over the following three decades, clinical reports concentrated on the now obsolete concept of "vertebrobasilar insufficiency"11 and on severe forms of pontine ischemia in the course of basilar artery thrombosis or in association with cerebellar infarcts. ${ }^{12-14}$ This contributed to the proposal of different new classifications of pontine stroke syndromes. ${ }^{15-17}$

The existence of isolated pontine strokes was reemphasized in the 1960s by C.M. Fisher. He described the syndromes of pure motor hemiparesis, dysarthria-clumsy hand, ataxic hemiparesis, and homolateral ataxia with crural paresis in association with small (lacunar) infarcts. ${ }^{18-20} \mathrm{He}$ also demon- 